\title{
The Most Important Skills Required by Local Public Health Departments for Responding to Community Needs and Improving Health Outcomes
}

\author{
Brandon Grimm ${ }^{1}$ (D) Athena K. Ramos ${ }^{2} \cdot$ Shannon Maloney $^{3} \cdot$ Chad Abresch $^{4} \cdot$ Melissa Tibbits $^{5} \cdot$ Kiara Lyons $^{6}$. \\ David Palm ${ }^{7}$
}

Accepted: 28 July 2021 / Published online: 13 August 2021

(c) The Author(s), under exclusive licence to Springer Science+Business Media, LLC, part of Springer Nature 2021

\begin{abstract}
In 2017, Public Health 3.0 was introduced, providing recommendations that expand traditional public department functions and programs. Operationalizing the framework requires that local health departments invest in the requisite professional skills to respond to their community's needs. The purpose of this paper is to determine the professional skills that are most important for local health departments to respond to large public health issues and challenges that are having a major impact on their communities. The study used a cross-sectional assessment of the education and training needs of local public health departments in Nebraska following the principles of practice-based systems research. The assessment was designed to assess the training and education needs of local health department staff members. The questions measured the perceived importance of and respondent's capacity across 57 core competencies for public health professionals modified from the Council on Linkages Between Academia and Public Health Practice. A total of 104 staff members from seven local health departments were requested to complete the assessment and $100 \%$ of the individuals responded to and completed the assessment. Twenty-eight skills were identified as the most important skills needed for local health departments. The skills were themed and categorized into four domains. (1) Data, Evaluation, and Quality Improvement, (2) Community Engagement and Facilitation, (3) Systems Thinking and Leadership, and (4) Policy and Advocacy. The results from this analysis provide direction to strengthen and transform the public health system into one that is connected, responsive, and nimble. Additionally, it also highlighted a glaring omission that Equity, Diversity, and Inclusion should be included as the fifth domain.
\end{abstract}

Keywords Public health practice · Capacity development · Local public health system · Competency assessment · Quality improvement

Brandon Grimm

blgrimm@unmc.edu

1 Office of Public Health Practice, College of Public Health, University of Nebraska Medical Center, Omaha, NE 68198-4335, USA

2 Department of Health Promotion, Center for Reducing Health Disparities, Central States Center for Agricultural Safety and Health (CS-CASH), Office of Latino Latin American Studies (UNO OLLAS), College of Public Health, University of Nebraska Medical Center, Omaha, NE 68198-4340, USA

3 Department of Health Promotion, College of Public Health, University of Nebraska Medical Center, Omaha, NE 68198-4340, USA
4 Department of Pediatrics, CityMatCH, Division of Child Health Policy, University of Nebraska Medical Center, Omaha, NE 68198-2155, USA

5 Department of Health Promotion, College of Public Health, University of Nebraska Medical Center, Omaha, NE 68198-4365, USA

6 Department of Pediatrics, CityMatCH, Division of Child Health Policy, University of Nebraska Medical Center, Omaha, NE 68198-2170, USA

7 Department of Health Services Research and Administration, College of Public Health, University of Nebraska Medical Center, Omaha, NE 68198-4350, USA 


\section{Introduction}

The current COVID-19 pandemic has illustrated the needs for a highly skilled public health workforce. As the public health system continues to evolve, it will require a workforce that is nimble, visionary, and ready for change [1]. The United States has made enormous strides toward improving population health, but significant challenges remain. Obesity and tobacco continue to be the leading causes of preventable death. Over the past decade we have seen a rise in deaths from drugs, alcohol, and suicide. Climate change has made extreme weather events more common, and all communities have struggled to reduce and eliminate health inequities [2].

Although federal and state public health agencies are expected to provide support, the primary responsibility for addressing these and other priorities is the local public health system that exists in communities. In addition to working on these priorities, local public health systems are leading community health needs assessments and community health improvement plans. However, COVID-19 has exposed the gaps in the capacity and the limitations of many local public health departments, particularly those in jurisdictions that serve a population of under 100,000 people.

Since the early 2000s, schools of public health and public health training centers have been assessing the education and training of public health practitioners using the Core Competencies for Public Health Professionals [3-6]. The Core Competencies for Public Health Professionals (Core Competencies) are a consensus set of skills for the broad practice of public health, as defined by the ten Essential Public Health Services. The current version of the Core Competencies was adopted in 2014 by the council on linkages between academia and public health practice and identify the skills recommended for public health professionals engaging in practice, education, and public health research [7].

However, these assessments have several weaknesses. For example, education and training needs have been reported in aggregate for all public health professionals in an entire state or region. Data presented in this way results in identifying the same education and training needs for professionals who work in widely different settings and disciplines of public health, even though the needs of these professionals likely differ [3-5, 8, 9]. In the past 5 years new frameworks and recommendations for training the current public health workforce have been developed. One widely known framework is the 2017 call to action titled Public Health 3.0. This framework was published to develop a renewed public health approach at the local level in the United States, providing recommendations that go beyond traditional public department functions and programs. At the core of Public Health 3.0 is the notion that local public health departments will support, become champions for, and drive community change to assure conditions that enable all people to thrive and be healthy [10]. Additionally, the de Beaumont Foundation and the Association of State and Territorial Health Officials have released recommendations to build a more prepared public health workforce, which have been widely acknowledged as important steps to strengthen the public health system and to positively impact public health outcomes in the Unites States [11, 12]. However, these recommendations have not been implemented at local public health departments. There are several reasons why this may be the case: (1) Limited formal training in public health at small local health departments, (2) staff wearing multiple hats, (3) multitude of competing priorities, and (4) it is unclear what skills are needed to operationalize the recommendations in practice.

Data from the most recent National Profile of Local Health Departments highlights many of these points. For example, $61 \%$ of all local health departments (LHDs) are considered small jurisdictions, covering a population < 50,000. The median full-time equivalent employees for LHDs with populations under 25,000 people is six, and for health departments with a population of 50,000-99,000, it is 26. Additionally, those health departments serving a population under 100,000 typically do not have an epidemiologist, a behavioral health specialist, data analysts, a public information specialist, and other critical staff. The majority of small jurisdictions cannot invest in quality improvement or capacity development of staff. In these small LHDs (serving a population under 100,000), there continues to be a lack of formal education and training in public health, and their median operating budgets is only $\$ 3.1$ million as compared to $\$ 6.9$ million in larger LHDs (serving a population of 100,000-249,999) [13].

In order for health departments to prioritize investments in developing critical workforce capacity, it is important to determine the gap between current and recommended skills in the public health workforce. The purpose of this paper is to determine those skills that are most important for local health departments to respond to large public health issues and challenges that are having a major impact on their communities such as health inequities, racism, climate change, and obesity.

\section{Methods}

Since 2015, faculty and staff from a midwestern College of Public Health have conducted a cross-sectional assessment of the education and training needs of local public health 
departments in following the principles of practice-based systems research [14]. The Institutional Review Board considers the assessments to be a quality improvement activity and not human subjects research; therefore, no IRB approval was necessary.

The local health departments in this study are part of a regionalized public health system that was formed in 2001 with support from tobacco settlement funds. The funds were used to establish 16 decentralized regional rural public health departments in addition to the three single county health departments that already existed to cover all 93 counties [15]. The legislative mandate required that each regional health department have at least 30,000 people and a minimum of three contiguous counties. Most of these regional health departments cover multiple counties over many square miles. For example, one local health department has 12 counties and covers over 11,000 square miles (approximately the size of the State of Maryland). The data analyzed for this assessment comes from seven rural health departments serving populations under 100,000 people. Each health department worked with the College of Public Health to create a workforce development plan to use for National Accreditation between 2018 and 2020. A total of 104 staff members from the seven local health departments completed the assessment since 2015.

The tool, initially developed in 2015 , was designed to assess the training and education needs of health department staff members. The assessment tool includes 130 questions divided into three sections. This paper presents findings from "Introduction" section, which measured the perceived importance of and respondent's capacity across a modified list of core competencies for public health professionals. "Methods" section of the survey included questions about preferred modes and settings for delivery of educational programs, and "Results" section focused on demographic characteristics of respondents.

"Introduction" section of the questionnaire is based on the 57 modified skills across the eight domains in the Core Competencies for Public Health Professionalism. This framework was used because it is an approved framework for national public health accreditation for local health departments. For the 57 skills, respondents indicated the level of importance of the skill to their work by using a 5-point Likert scale, in which $0=$ not applicable or I don't know, $1=$ not at all important, $2=$ slightly important, $3=$ moderately important, and $4=$ highly important. Respondents also assessed their capacity to carry out the skills by using a 5-point Likert scale, in which $0=$ not applicable or I don't know, $1=\mathrm{I}$ am unaware or have very little knowledge of the item, $2=\mathrm{I}$ have heard of it but have limited knowledge and/or ability to apply the skill, $3=\mathrm{I}$ am comfortable with knowledge or ability to apply the skill, and $4=\mathrm{I}$ am very comfortable, an expert, and could teach this skill to others. We combined responses of 1 or 2 into a "low" category and responses of 3 or 4 into a "moderate-to-high" category. We excluded responses of 0 from analysis and reported them as missing data. Next, for each of the 57 skills, we calculated the percentages of all respondents who perceived the skill to be low importance, low capacity, moderate-to-high importance, and moderateto-high capacity. We defined the skills for which training, and education were needed as those for which the percentage of respondents perceiving moderate-to-high importance was at least 15 percentage points higher than the percentage of respondents perceiving moderate-to-high capacity. Additional details about the survey and analysis methodology can be found in previous studies $[8,16]$. For this analysis, we went a step further in that only those council on linkages skills across the eight domains that were identified by at least $50 \%$ of the health departments as a training need were included. These skills were identified as the most important skills needed for local health departments to respond to public health issues and challenges impacting their communities. Finally, a qualitative analysis was completed to examine each of the council on linkages skills that were identified as training needs to look for patterns and relationships. Based on these relationships, themes were identified to create new domains. Finally, using the themes and domains, definitions for each domain were established.

\section{Results}

Since 2018, all staff $(n=104)$ from seven health departments serving a population of $<100,000$ have completed the education and training needs assessment. The majority of the respondents had at least a bachelor's degree (63.1\%), had worked at their health department for 5 years or less $(66 \%)$, and estimated they would retire in more than 10 years (68.9\%) (Table 1). The size of each health department in terms of both population covered (using most current census data) and number of employees varied. The seven health departments in the analysis served a total population of 440,956 (23\%) of the state's population of 1.9 million residents and over half of the 93 counties. The smallest health department served a population of 30,755 across nine counties and the largest health department served a population of 99,159 across seven counties. The number of employees in these health departments ranged from 36 in the largest department to 5 employees in the smallest department (Table 2).

Of the 57 skills identified in the Council on Linkages Core Competencies for Public Health Professionals, 50 were identified by at least one of the seven health departments as a training need (e.g., a variance of at least $15 \%$ between importance and capacity) and 28 were identified by at least four of the seven health departments. Six of the 
Table 1 Work-related and educational characteristics professional public health staff across seven local health departments in Nebraska $(\mathrm{n}=104)$

\begin{tabular}{lc}
\hline Characteristics & Respondents, no. $(\%)$ \\
\hline Education (n=104) & \\
High school/GED & $21(20.2)$ \\
Associate's degree & $17(16.3)$ \\
Bachelor's degree & $46(44.2)$ \\
Graduate certificate & $5(4.8)$ \\
Master's degree & $15(14.4)$ \\
Terminal degree (MD, JD, PharmD, PhD) & $0(0)$ \\
Time working at Local Health Department (in years; $\mathrm{n}=103)$ & \\
$0-2$ & $38(36.9)$ \\
$3-5$ & $30(29.1)$ \\
$6-10$ & $18(17.5)$ \\
$11-20$ & $16(15.5)$ \\
$>20$ & $1(1.0)$ \\
Estimated time until retirement (in years; $n=103)$ & \\
$0-5$ & $8(7.8)$ \\
$6-10$ & $7(6.8)$ \\
$>10$ & $71(68.9)$ \\
Not sure & $17(16.5)$ \\
\hline
\end{tabular}

Table 2 Size (population served and employees) of each of the local health departments

\begin{tabular}{|c|c|c|c|}
\hline $\begin{array}{l}\text { Local health } \\
\text { department } \\
\text { (LHD) }\end{array}$ & Population served & $\begin{array}{l}\text { Number of coun- } \\
\text { ties }\end{array}$ & $\begin{array}{l}\text { Number of } \\
\text { employees }\end{array}$ \\
\hline 1 & 99,159 & 17 & 9 \\
\hline 2 & 84,203 & 12 & 15 \\
\hline 3 & 78,388 & 3 & 36 \\
\hline 4 & 56,447 & 4 & 15 \\
\hline 5 & 53,536 & 5 & 16 \\
\hline 6 & 38,468 & 9 & 5 \\
\hline 7 & 30,755 & 9 & 8 \\
\hline Total & $\begin{array}{l}440,956 \text { (total } \mathrm{NE} \\
\text { population }=1.9 \\
\text { million) }\end{array}$ & $\begin{array}{l}49(52.7 \% \text { of the } \\
\text { total } 93 \text { counties } \\
\text { in NE) }\end{array}$ & \\
\hline
\end{tabular}

skills identified had a variance between 20 and $29 \%$. Fourteen skills had variance between 30 and $39 \%$, seven had a variance between 40 and $49 \%$ and one had a variance of over $50 \%$ (Table 3 ).

The 28 skills that were identified by at least 4 of the participating health departments were categorized into four domains with definitions based on themes qualitative analysis (Table 4):

1. Data, Evaluation, and Quality Improvement: The ability to locate, create, and use data for setting metrics, determining success, developing programs, and improving outcomes in the community and internally within the health department.
2. Community Engagement and Facilitation: The ability to build trusting, engaging, and sustainable partnerships with communities using diverse and appropriate facilitation techniques.

3. Systems Thinking and Leadership: The ability to use a systems-thinking lens to forecast and lead the changing dynamics of public health.

4. Policy and Advocacy: The ability to use data and evidence to develop and effectively advocate for public health policies that impact communities.

Fourteen of the skills were categorized in the Data, Assessment, and Quality Improvement domain. Five of the skills were categorized in the Community Engagement and Facilitation and the Systems Thinking and Leadership domain. Four skills were included in Policy and Advocacy domain. The top five skills in relation to variance between importance and capacity were in the Data, Assessment, and Quality Improvement domain and the Policy and Advocacy Domain. Additionally, of the top ten skills with the largest variance, six were from the Data, Assessment, and Quality Improvement domain.

\section{Discussion}

The results of this analysis provide clear domains for training, definitions, and skills needed for local health departments to respond to large public health issues impacting communities. We can use the example of the COVID-19 
Table 3 Skills identified as training needs by at least half of the seven health departments

\begin{tabular}{|c|c|c|c|}
\hline Skill & $\begin{array}{l}\text { No. }(\%) \text { of LHDs } \\
\text { identifying as a } \\
\text { need }\end{array}$ & $\begin{array}{l}(\%) \text { Variance between } \\
\text { importance and capac- } \\
\text { ity }\end{array}$ & Domain \\
\hline $\begin{array}{l}\text { Develop evaluation plans to monitor programs for } \\
\text { their effectiveness and quality }\end{array}$ & $5(71.4)$ & 55 & Data, Assessment, and Quality Improvement \\
\hline Describe the implications of public health policies & $5(71.4)$ & 49 & Policy and Advocacy \\
\hline Conduct program evaluations & $7(100)$ & 43 & Data, Evaluation, and Quality Improvement \\
\hline Develop work plans to implement programs & $5(71.4)$ & 42 & Data, Assessment, and Quality Improvement \\
\hline $\begin{array}{l}\text { Locate and apply information relevant to public } \\
\text { health policy issues (e.g. procedures, regulations } \\
\text { and laws) }\end{array}$ & $6(85.7)$ & 42 & Policy and Advocacy \\
\hline $\begin{array}{l}\text { Develop health information at appropriate literacy } \\
\text { levels }\end{array}$ & $4(57.1)$ & 42 & Data, Assessment, and Quality Improvement \\
\hline $\begin{array}{l}\text { Use appropriate facilitation techniques to encour- } \\
\text { age community involvement }\end{array}$ & $7(100)$ & 42 & Community Engagement and Facilitation \\
\hline $\begin{array}{l}\text { Distill results from data relevant to the community } \\
\text { or population served }\end{array}$ & $5(71.4)$ & 41 & Data, Assessment, and Quality Improvement \\
\hline $\begin{array}{l}\text { Manage programs consistent with public health } \\
\text { laws and regulations }\end{array}$ & $7(100)$ & 39 & Policy and Advocacy \\
\hline $\begin{array}{l}\text { Use information technology (i.e., databases) to col- } \\
\text { lect, store, and retrieve data }\end{array}$ & $4(57.1)$ & 38 & Data, Assessment, and Quality Improvement \\
\hline $\begin{array}{l}\text { Use community input when developing public } \\
\text { health policies and programs }\end{array}$ & $6(85.7)$ & 38 & Community Engagement and Facilitation \\
\hline $\begin{array}{l}\text { Use evaluation results (internal or external) to } \\
\text { improve programs }\end{array}$ & $7(100)$ & 37 & Data, Assessment, and Quality Improvement \\
\hline Ensure participation of key stakeholders & $7(100)$ & 36 & Community Engagement and Facilitation \\
\hline $\begin{array}{l}\text { Assess public health programs for their cultural } \\
\text { competence }\end{array}$ & $4(57.1)$ & 35 & Data, Assessment, and Quality Improvement \\
\hline $\begin{array}{l}\text { Implement strategies for continuous quality } \\
\text { improvement }\end{array}$ & $6(85.7)$ & 34 & Data, Assessment, and Quality Improvement \\
\hline $\begin{array}{l}\text { Modify individual practices with changing social, } \\
\text { political, and/or economic situations }\end{array}$ & $5(71.4)$ & 34 & Systems Thinking \& Leadership \\
\hline $\begin{array}{l}\text { Know who to contact or where to find laws, regula- } \\
\text { tions and procedures for research, surveillance } \\
\text { and evaluation }\end{array}$ & $7(100)$ & 33 & Systems Thinking \& Leadership \\
\hline Identify factors to measure public health conditions & $5(71.4)$ & 32 & Data, Assessment, and Quality Improvement \\
\hline $\begin{array}{l}\text { Develop strategies for continuous quality improve- } \\
\text { ment }\end{array}$ & $6(85.7)$ & 31 & Data, Assessment, and Quality Improvement \\
\hline $\begin{array}{l}\text { Participate with stakeholders to identify key values } \\
\text { and shared vision for the benefit of communities } \\
\text { or populations served }\end{array}$ & $5(71.4)$ & 31 & Community Engagement and Facilitation \\
\hline Identify the ten essential services of Public Health & $5(71.4)$ & 30 & Data, Assessment, and Quality Improvement \\
\hline $\begin{array}{l}\text { Locate and use scientific evidence to address a } \\
\text { public health issue, concern, or intervention }\end{array}$ & $5(71.4)$ & 30 & Data, Assessment, and Quality Improvement \\
\hline Develop work plans to implement policies & $5(71.4)$ & 27 & Policy and Advocacy \\
\hline $\begin{array}{l}\text { Aware of internal and external influences that may } \\
\text { affect the delivery of public health services }\end{array}$ & $6(85.7)$ & 26 & Systems Thinking \& Leadership \\
\hline $\begin{array}{l}\text { Explain the dynamic forces that contribute to } \\
\text { cultural diversity }\end{array}$ & $5(71.4)$ & 26 & Systems Thinking \& Leadership \\
\hline $\begin{array}{l}\text { Assess the health literacy of populations served } \\
\text { (Can the population understand the information } \\
\text { provided?) }\end{array}$ & $6(85.7)$ & 25 & Data, Assessment, and Quality Improvement \\
\hline $\begin{array}{l}\text { Inquire about and use available community assets } \\
\text { and resources }\end{array}$ & $5(71.4)$ & 25 & Community Engagement and Facilitation \\
\hline $\begin{array}{l}\text { Able to participate in and resolve conflict produc- } \\
\text { tively }\end{array}$ & $6(85.7)$ & 23 & Systems Thinking \& Leadership \\
\hline
\end{tabular}


Table 4 Most important domains and skills needed in local health departments to respond to large public health issues and challenges impacting their communities

\begin{tabular}{|c|c|}
\hline Domain & Skills \\
\hline $\begin{array}{l}\text { Data, Assessment, and Quality Improvement: The ability to locate, } \\
\text { create, and use data for setting metrics, determining success, devel- } \\
\text { oping programs, and improving outcomes in the community and } \\
\text { internally within the health department }\end{array}$ & $\begin{array}{l}\text { Develop evaluation plans to monitor programs for their effectiveness } \\
\text { and quality } \\
\text { Conduct program evaluations } \\
\text { Distill results from data relevant to the community or population served } \\
\text { Use information technology (i.e. databases) to collect, store, and } \\
\text { retrieve data } \\
\text { Use evaluation results (internal or external) to improve programs } \\
\text { Identify factors to measure public health conditions } \\
\text { Locate and use scientific evidence to address a public health issue, } \\
\text { concern, or intervention } \\
\text { Assess public health programs for their cultural competence } \\
\text { Assess the health literacy of populations served (Can the population } \\
\text { understand the information provided?) } \\
\text { Develop health information at appropriate literacy levels } \\
\text { Develop work plans to implement programs } \\
\text { Implement strategies for continuous quality improvement } \\
\text { Develop strategies for continuous quality improvement } \\
\text { Identify the ten essential services of Public Health }\end{array}$ \\
\hline $\begin{array}{l}\text { Community Engagement and Facilitation: The ability to build trusting, } \\
\text { engaging, and sustainable partnerships with the community using } \\
\text { diverse and appropriate facilitation techniques }\end{array}$ & $\begin{array}{l}\text { Use appropriate facilitation techniques to encourage community } \\
\text { involvement } \\
\text { Use community input when developing public health policies and } \\
\text { programs } \\
\text { Ensure participation of key stakeholders } \\
\text { Participate with stakeholders to identify key values and shared vision } \\
\text { for the benefit of communities or populations served } \\
\text { Inquire about and use available community assets and resources }\end{array}$ \\
\hline $\begin{array}{l}\text { Systems Thinking and Leadership: The ability to use a systems- } \\
\text { thinking lens to forecast and lead with changing dynamics of public } \\
\text { health }\end{array}$ & $\begin{array}{l}\text { Modify individual practices with changing social, political, and/or } \\
\text { economic situations } \\
\text { Aware of internal and external influences that may affect the delivery of } \\
\text { public health services } \\
\text { Explain the dynamic forces that contribute to cultural diversity } \\
\text { Know who to contact or where to find laws, regulations and procedures } \\
\text { for research, surveillance and evaluation } \\
\text { Able to participate in and resolve conflict productively }\end{array}$ \\
\hline $\begin{array}{l}\text { Policy and Advocacy: The ability to use data and evidence to develop } \\
\text { and advocate for effective public health policies that impact com- } \\
\text { munities }\end{array}$ & $\begin{array}{l}\text { Locate and apply information relevant to public health policy issues } \\
\text { (e.g., procedures, regulations and laws) } \\
\text { Manage programs consistent with public health laws and regulations } \\
\text { Describe the implications of public health policies } \\
\text { Develop work plans to implement policies }\end{array}$ \\
\hline
\end{tabular}

pandemic to better understand how these skills could have changed the public health department response. For example, if all LHD's had staff with the skills identified in Data, Evaluation, and Quality Improvement, communities may have been better prepared to identify hotspots earlier, identify groups most at risk, and forecast upcoming threats. Additionally, if LHD's had staff with the skills identified in the community engagement and facilitation domain, they may have already had trusting relationships with their community partners and they could have immediately started working with their partners, such as meat processing companies, schools, social service agencies, long-term care, and community-based organizations working with racial and ethnic minorities. Finally, if LHDs had staff with the skills related to system thinking and leadership and policy and advocacy they may have had the ability to forecast the changing dynamic of the pandemic and also been able to work with their elected officials to establish policies related to public health authorities, dispersion of resources, and other issues. 
The COVID-19 pandemic has highlighted the historic way that LHDs traditionally focus on large public health threats-by attempting to assume all the responsibility to solve the issues. Examples of this are illustrated in the development and implementation of Community Health Improvement Plans, chronic disease management, environmental health issues, and many other public health issues. LHDs need to be able to create change in systems and communities through collaborations that regularly engage partners at different levels and across different sectors $[17,18]$. This would allow all to become more aware of factors that influence community health and well-being and the interconnected nature of public health. Further, it would also allow LHD's to have developed trusting relationships with these partners, which may not only enhance the sustainability of the current work, but also speed response during a public health emergency. To improve care coordination and address the social determinants of health, LHDs need to work closely with primary care clinics, small rural hospitals, behavioral health organizations, the housing authority, and social service organizations [19]. Local health departments must also set clear metrics to document success and use and share real-time data impacting community health.

Beyond just highlighting the skills, developing them requires a focused training plan and recommendations for LHDs to instill the skills in practice. Training plans need to build knowledge in these areas that leads to change in behaviors. It is recommended that training plans use the Kirkpatrick model to develop training plans that move from satisfaction of training to behaviors and outcomes [20]. Developing training plans that will do this requires a commitment. All programs and schools of public health should focus on developing these skills within the future public health workforce. They should challenge their faculty to incorporate capacity development with practitioners into their community-based research and service initiatives. It is not enough to simply collect data or implement programs. It is imperative that we also build the capacity of the community and those individuals responsible for assuring the health of the community. Additionally, the Public Health Training Center (PHTC) network should focus on providing training related to these skills with the current public health workforce.

\section{Public Health Implications}

If LHDs were able to build capacity (i.e., the skills outlined in Table 4) and hire new staff with the identified skills, then they would be able to operationalize Public Health 3.0 and position themselves to become the "chief health strategist" for their communities. Additionally, local health departments should consider forming academic health departments. An academic health department is a formal affiliation between a local or state health department and an academic institution. It is the public health equivalent to a teaching hospital [21]. Establishing agreement with schools of public health, allow for partnerships for cross jurisdictional agreements or mutual aid agreements to share epidemiologists or data managers since these positions may not exist in small rural health departments [22]. Data is at the core of public health, and practitioners should use data to drive decision-making and policy change, prioritize interventions, and demonstrate success. Practitioners need basic skills in evaluation and quality improvement, but they also need to partner with those that can analyze big data for precision public health [22].

Finally, these are not the only skills needed within a health department. One area that is glaringly missing includes the skills related to inclusion, diversity, and equity. These skills were not identified from the analysis of current data because they are not adequately addressed in the survey tool and specific skills need to be determined. The Council on Linkages Core Competencies focus on cultural competency skills, which are different than those related to inclusion, diversity and equity. This is also true for the recently revised core functions and essential public health services. Equity is at the center of the wheel and there is a definition of equity however there are not skills or essential services associated with equity [23]. It is recommended that a domain related to diversity, inclusion and equity with specific skills be included to any capacity development framework for local health departments moving forward. The COVID-19 pandemic has shined a spotlight on our nation's public health system. Although this crisis has exposed clear weaknesses in the public health infrastructure, it also provides new opportunities to strengthen and transform this system into one that works for all and is connected, responsive, nimble, and reflective of the values of equity and inclusion. Public Health 3.0 was the first call to action. The recommendations proposed in this paper provide guidance for health departments to have the necessary skills to assure the conditions so that all individuals in their communities can be healthy and thrive.

\section{References}

1. Turnock, B. J. (2016). Essentials of public health. Jones \& Bartlett Learning.

2. The Impact of Chronic Underfunding on America's Public Health System: Trends, Risks, and Recommendations. tfah.org. https:// www.tfah.org/reports/. Published April 2020. Accessed June 10, 2020.

3. Andreen, J. E., \& Gove, C. (2014). Alaska's community capacity review: a statewide public health system assessment. http:// hss.state.ak.us/ha2020/assets/HA2020_2014CCR.pdf. Published 2014. Accessed April 5, 2017. 
4. Southeast Public Health Training Center. (2014). A statewide report on the public health workforce in local health departments in North Carolina, 2013. https://sph.unc.edu/files/2014/02/nciphStatewide-workforce-rep.pdf. Published 2014. Accessed April 5, 2017.

5. Harrison, L. M., Davis, M. V., MacDonald, P. D. M., Alexander, L. K., Cline, J. S., Alexander, J. G., Rothney, E. E., Rybka, T. P., \& Stevens, R. H. (2005). Development and implementation of a public health workforce training needs assessment survey in North Carolina. Public Health Reports, 120(Suppl 1), 28-34. https://doi. org/10.1177/00333549011200S107

6. Sellers, K., Leider, J. P., Harper, E., Castrucci, B. C., Bharthapudi, K., Liss-Levinson, R., Jarris, P. E., \& Hunter, E. L. (2015). The public health workforce interests and needs survey: The first national survey of state health agency employees. Journal of Public Health Management and Practice, 21(Suppl 6), S13-S27. https://doi.org/10.1097/PHH.0000000000000331

7. Public Health Foundation, Council on Linkages Between Academia and Public Health Practice. (2014). Core competencies for public health professionals. http://www.phf.org/resourcestools/ pages/core_public_health_competencies.aspx. Published 2014. Accessed June 10, 2020.

8. Grimm, B., Arcari, C., Ramos, A., LeVan, T., Brandert, K., King, K., Siahpush, M., Michaud, T., Johansson, P., Burke, C., \& Topko, L. (2019). Creating customized workforce development plans for medium-to-large public health departments. Public Health Reports, 134(4), 395-403. https://doi.org/10.1177/0033354919 853255

9. Grimm, B. L., Johansson, P., Nayar, P., Apenteng, B. A., Opoku, S., \& Nguyen, A. (2015). Assessing the education and training needs of Nebraska's public health workforce. Frontiers in Public Health, 3, 161. https://doi.org/10.3389/fpubh.2015.00161

10. Desalvo, K. B., Wang, Y. C., Harris, A., Auerbach, J., Koo, D., \& O'Carroll, P. (2017). Public Health 3.0: A call to action for public health to meet the challenges of the 21 st century. Preventing Chronic Disease. https://doi.org/10.5888/pcd14.170017

11. Flores, A. L., et al. (2019). Building skills for a more strategic health workforce: A call to action. De Beaumont Foundation, 13 May 2019, http://www.debeaumont.org/news/2017/buildingskills-for-a-more-strategic-health-workforce-a-call-to-action/.

12. Fraser, M., \& Castrucci, B. C. (2017). Beyond the status quo. Journal of Public Health Management and Practice, 23(5), 543551. https://doi.org/10.1097/phh.0000000000000634

13. National Profile of Local Health Departments. NACCHO. (2019). https://www.naccho.org/profile-report-dashboard. Published 2019. Accessed June 10, 2020.

14. Association of Schools and Programs of Public Health. (2006). Demonstrating excellence in practice-based research for public health. http://www.aspph.org/educate/models/demonstrating-excel lence-in-practice-based-research-for-public-health. Published 2006. Accessed June 10, 2020.

15. Turning Point: Collaborating for a New Century in Public Health. 25 May 2018. http://www.rwjf.org/en/library/research/2008/05/ turning-point-.html.

16. Grimm, B. L., Brandert, K., Palm, D., \& Svoboda, C. (2016). The EDIC method: An engaging and comprehensive approach for creating health department workforce development plans. Health Promotion Practice, 18(5), 688-695. https://doi.org/10.1177/ 1524839916671301

17. Harris, J. K., Leider, J. P., Carothers, B. J., Castrucci, B. C., \& Hearne, S. (2016). Multisector health policy networks in 15 large US cities. Journal of Public Health Management and Practice, 22(6), 520-528. https://doi.org/10.1097/phh.0000000000000401

18. Varda, D. M., Chandra, A., Stern, S. A., \& Lurie, N. (2008). Core dimensions of connectivity in public health collaboratives. Journal of Public Health Management and Practice, 14(5), E1-E7. https://doi.org/10.1097/01.phh.0000333889.60517.46

19. Khoury, M. J., Iademarco, M. F., \& Riley, W. T. (2016). Precision public health for the era of precision medicine. American Journal of Preventive Medicine, 50(3), 398-401. https://doi.org/10.1016/j. amepre.2015.08.031

20. Kirkpatrick, D. L., \& Kirkpatrick, J. D. (2006). Evaluating training programs: The four levels (3rd ed.). Berrett-Koehler; McGraw-Hill Distributor.

21. Academic Health Departments: Core Concepts. Public Health Foundation-Home. The Council on Linkages Between Academia and Public Health Practice, 14 Jan. 2011. http://www.phf.org/.

22. Enanoria, W. T., Crawley, A. W., Hunter, J. C., Balido, J., \& Aragon, T. J. (2014). The epidemiology and surveillance workforce among local health departments in California: Mutual aid and surge capacity for routine and emergency infectious disease situations. Public Health Reports, 129(6_suppl4), 114-122. https://doi.org/10.1177/00333549141296s415

23. Centers for Disease Control and Prevention. (2021). 10 Essential Public Health Services. https://www.cdc.gov/publichealthgat eway/publichealthservices/essentialhealthservices.html. Published March 2021. Accessed July 6, 2021.

Publisher's Note Springer Nature remains neutral with regard to jurisdictional claims in published maps and institutional affiliations. 